\title{
The immunomodulatory effect of inhaled granulocyte-macrophage colony-stimulating factor in cystic fibrosis. A new treatment paradigm
}

This article was published in the following Dove Press journal:

Journal of Inflammation Research

19 January 2012

Number of times this article has been viewed

Lars Heslet ${ }^{1}$

Christiane Bay ${ }^{2}$

Steen Nepper-Christensen ${ }^{3}$

'Serendex ApS, Gentofte, Denmark; ${ }^{2}$ University of Copenhagen, Medical Faculty, Copenhagen, Denmark; ${ }^{3}$ Department of Head and Neck Surgery, Otorhinolaryngology, Køge Hospital, Denmark
Correspondence: Steen Nepper-

Christensen

Department of Head and Neck Surgery, Otorhinolaryngology, Køge Hospital, Lykkebækvej I, 4600 Køge, Denmark $\mathrm{Tel}+4547313810$

Email nepper@dadlnet.dk
Background: Patients with cystic fibrosis (CF) experience recurrent infections and develop chronically infected lungs, which initiates an altered immunological alveolar environment. Endstage pulmonary dysfunction is a result of a long sequence of complex events in CF, progressing to alveolar macrophage dysfunction via a T-helper $2\left(\mathrm{~T}_{\mathrm{H}} 2\right)$ dominated alveolar inflammation with CD20 T-cell activation, induced by the chronic infection and showing a poor prognosis. There is great potential for treatment in transforming the $\mathrm{T}_{\mathrm{H}} 2$ into the more favorable T-helper $1\left(\mathrm{~T}_{\mathrm{H}} 1\right)$ response.

Methods: Current literature in the PubMed database and other sources was reviewed in order to evaluate aspects of the innate alveolar host defense mechanisms and the potential impact on the immunoinflammatory response of inhalation of granulocyte-macrophage colony-stimulating factor (GM-CSF) in patients with CF.

Results: It seems that the cellular host defense, (ie, the alveolar macrophage and neutrocyte function) and the inhaled GM-CSF interact in such a way that the so-called tolerant alveolar environment dominated by the $\mathrm{T}_{\mathrm{H}} 2$ response may be transformed into an active $\mathrm{T}_{\mathrm{H}} 1$ state with a normal pulmonary host defense. The shift of the $\mathrm{T}_{\mathrm{H}} 2$ to the $\mathrm{T}_{\mathrm{H}} 1$ subset dominated by specific and unspecific antibodies may be achieved after the inhalation of GM-CSF. A clinical report has shown promising results with inhalation of GM-CSF in a chronically-infected CF patient treated with several antibacterial and antifungal agents. Inhaled GM-CSF transformed the tolerance toward the Gram-negative infection reflected by the so-called $\mathrm{T}_{\mathrm{H}} 2$ subset into the more acute $\mathrm{T}_{\mathrm{H}} 1$ response characterized by recruitment of the T-cells CD8 and CD16, a condition related to better-preserved lung function. This indicated a transformation from a state of passive bacterial tolerance toward the Gram-negative infecting and colonizing bacteria. This GM-CSF effect cannot be achieved by administering the drug via the IV route because the drug is water-soluble and too large to penetrate the alveolocapillary membrane.

Conclusions: Inhalation of GM-CSF seems to be a novel way to positively modulate the alveolar environment toward an altered immunological state, reflected by a positive change in the pattern of surrogate markers, related to better preservation of pulmonary function and thus improved outcomes in CF patients. It is suggested that future studies examining standard endpoint variables such as number of infections and amount of antibiotics used should be supplemented by surrogate markers, to reveal any positive cellular and cytokine responses reflecting changes in the alveolar compartment after GM-CSF inhalation. The immunological alveolar environment should be monitored by a specific pattern of surrogate markers. Continued research is clearly indicated and the role of inhaled GM-CSF in modulating pulmonary host defense in CF patients should be investigated in a large study.

Keywords: cystic fibrosis, granulocyte-macrophage colony-stimulating factor, $\mathrm{T}_{\mathrm{H}} 1$ response, $\mathrm{T}_{\mathrm{H}} 2$ subset, surrogate markers 


\section{Introduction}

Patients with cystic fibrosis $(\mathrm{CF})$ are subject to recurrent and chronic lung infections due to impairment of the natural host defenses of their airways. ${ }^{1}$ End-stage pulmonary dysfunction in $\mathrm{CF}$ is a result of a long sequence of recurrent infections and colonizations that induce alveolar macrophage dysfunction via a T-helper 2 cell $\left(\mathrm{T}_{\mathrm{H}} 2\right)$ dominated alveolar inflammation. ${ }^{2}$ The $\mathrm{T}_{\mathrm{H}} 2$ response is tolerant toward multiple infections. ${ }^{3}$

The cystic fibrosis transmembrane conductance regulator chloride channel (CFTR) plays a central role in bactericidal activity both in the neutrocyte and the macrophage. The defective CFTR-/- macrophages have reduced intracellular acidification and a Gram-negative infection initiates an alveolar $\mathrm{T}_{\mathrm{H}} 2$ response with $\mathrm{B}$-cell activation resulting in antibody formation. ${ }^{4}$ In this way the response is transformed from the normal alveolar host defense into the well characterized immunologic and allergic alveolar disorder accompanied by increased systemic immunoglobulin formation, which contributes to the pathogenesis of $\mathrm{CF}^{4}{ }^{4}$ The $\mathrm{T}_{\mathrm{H}} 2$ response has been connected with an unfavorable and accelerated decline in lung function. ${ }^{5}$ End-stage alveolar macrophage dysfunction is reflected by reduced antigen (Ag) presentation, ${ }^{6}$ enhanced tolerance toward lipopolysaccharide (LPS), ${ }^{1,7}$ and reduced expression of recognition receptors, the socalled toll-like receptors (TLR), where TLR4 recognizes Gram-negatives. ${ }^{8}$ The reduced alveolar host defense may also induce remodeling of the peripheral airways, leading to a fall in lung function which ultimately results in pulmonary failure. ${ }^{9}$ This pathogenic step is only seen to affect the pulmonary host defense: circulating monocytes that are not yet exposed to interaction in the specific pulmonary milieu seem unaffected, even though all host cells are supposed to be affected equally by the congenital CFTR mutation. ${ }^{10}$ Ongoing stimulation of the LPS binding receptor (CD14+) on the alveolar host cells causes receptor internalization and induces a state of LPS tolerance and subsequently hyperinflammation (Figure 1). ${ }^{1}$ The same unresponsiveness of the host cells is suspected in the sinuses, where a finding of chronic sinusitis with bacterial colonization is almost ubiquitous in the CF patient, ${ }^{11}$ potentially serving as a bacterial reservoir leading to recolonization of the lungs after antibacterial eradication of the lung infection. ${ }^{12}$

The dominant microbiological etiology of the chronic infections is Pseudomonas aeruginosa, Staphylococcus aureus, Burkholderia cepacia complex, Achromobacter xylo- soxidans and Mycobacterium abscessus/chelonae. These are frequently isolated from CF lungs. ${ }^{13}$ Microorganisms such as P. aeruginosa find a niche in the alveolar environment due to a whole host of bacterial survival "strategies" - the so-called bacterial "stealth strategy" - including mucoid exopolysaccharide production and biofilm formation, evading both the host defense system and antibiotic therapy. Once the lungs are chronically infected it is impossible to eliminate the causative agent. The ongoing colonization induces antibiotic resistance, ${ }^{14}$ which results in a continuous reduction of lung function due to destruction of the lung tissue induced by the excessive inflammation. ${ }^{15} \mathrm{~A}$ high or rapidly increasing number of anti-Pseudomonas antibodies has been correlated to a poor prognosis, while CF patients with a low number of anti-Pseudomonas antibodies show an improved outcome with chronic P. aeruginosa lung infection. ${ }^{16} \mathrm{~T}_{\mathrm{H}}$-cells are subdivided into two subsets based on their cytokine pattern: $\mathrm{T}_{\mathrm{H}} 1$ pattern cells are characterized by IFN- $\gamma$, production and activation of macrophages, and induction of cellular T-cell responses. In contrast, the $\mathrm{T}_{\mathrm{H}} 2$ pattern produces IL-4, IL-5, IL-9, and IL-13 and is characterized by increased CD20 T-cells (Table 1). ${ }^{17}$

Increased IL- 4 and reduced IFN- $\gamma$ release from peripheral blood mononuclear cells (PBMCs) stimulated with Pseudomonas antigen has been demonstrated. ${ }^{18}$

\section{Inhaled GM-CSF and the $T_{H} I$ subset}

The beneficial $\mathrm{T}_{\mathrm{H}} 1$ subset may be induced by GM-CSF: T-lymphocytes are recruited into the alveolus as are antigenpresenting alveolar macrophages. The $\mathrm{T}_{\mathrm{H}} 2$ subset causing the tolerance towards the ever-present Pseudomonas species in the alveolar environment is downregulated by the inhaled GM-CSF. This makes inhaled GM-CSF a highly interesting new drug for inhalation with respect to alveolar immunomodulation. In addition, inhaled GM-CSF stays in the alveolus with no spill-over to the circulation and thus has no systemic adverse effects. ${ }^{19}$

Research has shown that chronically-infected CF patients with the highest IFN- $\gamma$ and IL-4 production also have the best-preserved lung function, indicating a beneficial potential for the modulation of the $\mathrm{T}_{\mathrm{H}} 1 / \mathrm{T}_{\mathrm{H}} 2$ balance. ${ }^{10}$

\section{Animal studies and modulation of the immune system}

It has been documented that IFN- $\gamma$ treatment of rats with chronic $P$. aeruginosa lung infection results in increased neutrophilic-induced pulmonary inflammation with less reactive mononuclear cells. ${ }^{24}$ 


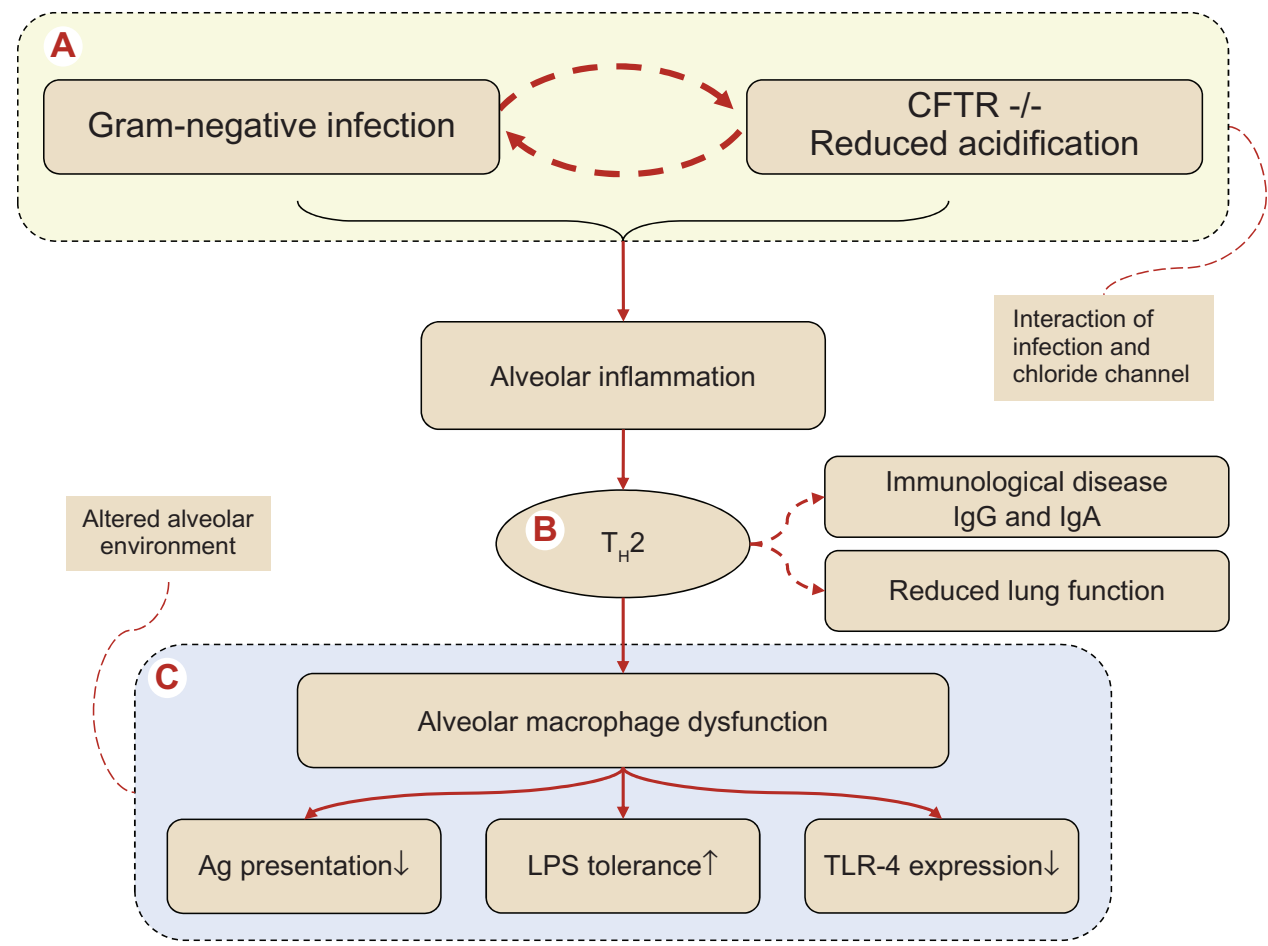

Figure I Pathogenesis of the complex series of events in cystic fibrosis (CF) progressing to alveolar macrophage dysfunction via a $\mathrm{T}_{\mathrm{H}} 2$ dominated alveolar inflammation. (A) Denotes the interaction between the defective cystic fibrosis transmembrane conductance regulator (CFTR) $)^{-/-}$macrophages in respect to intracellular acidification and Gram-negative infection, an interaction involving a T-cell switch (B) to an alveolar T-helper 2 response with induction of B-cell activation with antibody formation, transforming CF into an immunological allergic disease characterized by increased systemic immunoglobulin formation (lgG and $\lg E$ ). The $T_{H} 2$ response has been connected with an unfavorable accelerated declined spirometry. The end stage of the altered alveolar environment (C) with alveolar macrophage dysfunction, reflected by (i) reduced antigen (Ag) presentation, (ii) enhanced tolerance toward lipopolysaccharide (LPS) and finally (iii) reduced expression of recognition receptors, the so-called toll-like receptors (TLR) where TLR-4, which recognizes Gram-negatives, is decreased. In the end, remodeling of peripheral airways will take place producing a reduced alveolar host defense.

A key cell in initiating and controlling the T-helper cell response is the dendritic cell (DC). Unless the DCs present and interact, naive T-cells will not be activated..$^{25}$ The resting alveolar macrophage will only be transformed into a DC if GM-CSF is present to stimulate the surface receptor of the alveolar macrophages (the autocrine function). ${ }^{26}$ It may be hypothesized that increased serum granulocyte colony-stimulating factor (G-CSF) could be the cause of the skewed $\mathrm{T}_{\mathrm{H}} 1 / \mathrm{T}_{\mathrm{H}}$ 2-ratio observed in CF. Moreover, several publications have reported that granulocyte GM-CSF can induce a $\mathrm{T}_{\mathrm{H}} 1$ dominated response through modulation of the DCs. ${ }^{27,28}$ Indeed, chronically-infected CF patients were observed to have a significantly decreased GM-CSF/G-CSF ratio as compared to $\mathrm{CF}$ patients without a chronic $P$. aeruginosa lung infection. ${ }^{5}$ Furthermore, this GM-CSF ratio correlated to the IFN- $\gamma$ release from peripheral blood mononuclear cells (PBMCs) and lung function, indicating a beneficial role for GM-CSF treatment in CF. GM-CSF is normally produced

Table I Comparison of two subsets $\mathrm{T}_{\mathrm{H}} \mathrm{I}$ and $\mathrm{T}_{\mathrm{H}} 2$ each consisting of $\mathrm{T}$-cells and a corresponding cytokine pattern

\begin{tabular}{|c|c|c|c|c|}
\hline Subset & Characterization & Clinical response & Surrogate variables* & References \\
\hline \multirow{5}{*}{$\overline{T_{H} \mathrm{I}}$} & Acute inflammatory response & T-cell recruitment from systemic & T-cells: & Brazova et al ${ }^{10}$ \\
\hline & orchestrated by the $\mathrm{AM}^{* * * *}$ & cellular pool via macrophage & CD8 and 16 & Eksioglu et $\mathrm{al}^{19}$ \\
\hline & after GM-CSF activation & antigen presentation & $T_{H} I$ cytokines: & Gonzalez-Juarrero et al ${ }^{20}$ \\
\hline & & & IL-I 2 and IFN- $\gamma$ & Moser et $\mathrm{al}^{18}$ \\
\hline & & & & Trapnell et $\mathrm{al}^{21}$ \\
\hline \multirow[t]{5}{*}{$\mathrm{T}_{\mathrm{H}^{2}} 2$} & Chronic host response & Inflammatory response related & T-cells: & Brazova et al ${ }^{10}$ \\
\hline & LPS tolerance & to chronic infection/colonization & CD20 + antibodies $\lg E^{* *}$ & Greenberger ${ }^{4}$ \\
\hline & Allergic response & Antibody producing cells & $\mathrm{T}_{\mathrm{H}} 2$ cytokines: & Knutsen et $\mathrm{al}^{22}$ \\
\hline & & via $C D 20$ cells & ILs 4 and I0 & Meneghin and Hogaboam ${ }^{23}$ \\
\hline & & & & Spellberg and Edwards ${ }^{17}$ \\
\hline
\end{tabular}

Notes: *Measurements performed in Bronchoalveolar lavage fluid (BALF); **Specific or unspecific antibodies measured in plasma;

Abbreviations: AM, alveolar macrophage, which after inhaled GM-CSF is transformed by the inhaled GM-CSF into an immune inflammatory competent dendritic cell; GM-CSF, granulocyte-macrophage colony-stimulating factor. 
locally by the alveolar macrophages,${ }^{21}$ being the first line of defense when clearing bacteria. ${ }^{29}$ The innate immune function of the alveolar macrophage is significantly influenced by subsequently acquired immune responses. ${ }^{30}$ The concentration of GM-CSF in the alveolar space is of utmost importance for the pulmonary host defense system.

Treatment of CF patients has hitherto focused on intensive long-term, high-dose, broad-spectrum antibiotics administered intravenously and by inhalation, combined with interventions aiming at enhanced clearance of mucus, eg, with DNA-ase.

\section{Inhalation versus intravenous administration}

Recently a paper discussed whether recombinant proteins should be inhaled or administered systemically in order to reach an alveolar target. ${ }^{31}$ In the context of the present review one may question which route of administration should be preferred, when one intervenes with GM-CSF.

It has been documented that inhaled GM-CSF increases the number and function of phagocytic cells obtained from bronchoalveolar lavage (BAL), but with only sparse and transient increase in the number of myeloid cells in circulation. ${ }^{32}$ Conversely, when administered intravenously (IV) there was only a limited response in alveolar cellularity. It follows that the pulmonary innate host defense is separated from the systemic defense system with respect to GM-CSF, and that the agent does not penetrate from the systemic circulation to the alveolar space or vice versa. ${ }^{32}$ IV administration of even relatively small molecules like recombinant antitrypsin does not reach the alveolar space, as shown by the fact that only $2 \%$ of the IV-administered drug reaches the lung space. ${ }^{33}$ For larger molecules like the recombinant protein Activated Protein C (APC), it has been documented that administered intravenously, APC had no effect even in the inflamed lung. ${ }^{34}$ However, when inhaled, APC achieved the expected effect in the alveolus, without any systemic adverse effects. ${ }^{35,36}$

GM-CSF neutralizing autoantibodies in pulmonary alveolar proteinosis (PAP) have led to a lack of phagocytic function of alveolar macrophages. ${ }^{37}$ Subcutaneous administration of GM-CSF has been tried in PAP to improve macrophage function, but only inhaled GM-CSF had an effect. ${ }^{38}$ The explanation is that anti-GM-CSF blocking autoantibodies are detected both in serum and BAL fluid from patients with PAP. ${ }^{39}$

A major point is the question of whether the inhaled drug reaches the GM-CSF receptors of alveolar macrophages in the peripheral airways.
By using a so-called micropump nebulizer, sufficiently small respirable aerosol particles with a size of $\sim 2.5 \mu \mathrm{m}$ are produced, which means that a high degree of peripheral lung deposition is obtained. ${ }^{40,41}$ Inhaled GM-CSF also appears safe because aerosol therapy did not cause any adverse effects in either lung cancer or in patients with pulmonary alveolar proteinosis. ${ }^{42-44}$ Based on these findings GM-CSF treatment may therefore be best inhaled rather than administered systemically.

\section{Immunomodulatory treatment}

Treating CF patients with GM-CSF inhalation has shown promising results. ${ }^{45}$ The drug was inhaled in a dose of $250 \mu \mathrm{g} /$ day for 1 week followed by 14 days' pause, for a total period of 3 months. The GM-CSF response was monitored by immunoglobulins IgG and IgE, cytokines, and spirometry (forced expiratory volume in 1 second, $\mathrm{FEV}_{1}$ ). Interestingly, it brought about a noteworthy cytokine increase, ie, an IFN- $\gamma$ increase from PBMCs activated with bacterial antigen.

Inhalation of GM-CSF was well tolerated without any signs or symptoms of pulmonary adverse effects, such as bronchoconstriction. The treatment seemed safe. None of the described findings following inhalation were documented after systemic GM-CSF therapy: ie, no switch in T-helper cell pattern and no change in immunologic allergic variables or cytokine response. It was not possible to document any effect in the alveolar space when systemic administration of GM-CSF or other biologics was used. These findings support the concept that the inhaled GM-CSF transformed the $\mathrm{T}_{\mathrm{H}} 2$ dominated alveolar condition into a $\mathrm{T}_{\mathrm{H}} 1$-like response (Table 1), a suggestion which is also in keeping with the fact that a $\mathrm{T}_{\mathrm{H}} 2$ response is seen when Aspergillus antigens appear in CF patients. ${ }^{22}$ During the period of inhaled GM-CSF intervention, a noteworthy increase in IFN- $\gamma$ release of PBMCs after stimulation with Mycobacterium abscessus antigen was noted, a $\mathrm{T}_{\mathrm{H}} 1$ response which was not demonstrated during systemic GM-CSF administration.

Furthermore it has been documented that transgenic mice overexpressing GM-CSF in alveolar epithelial cells have an enhanced resistance towards influenza by activation of the alveolar immune mechanisms that depend on alveolar macrophages. ${ }^{46}$ These mice were highly resistant to infection with laboratory and clinical influenza strains, including the pandemic swine H1N1 strain. The mice had reduced lung injury and reduced mortality after influenza infection. They also showed increased levels of TNF- $\alpha$ and evidence of mononuclear cell infiltrates after infection. The histological findings suggested that the mice mounted a rapid 
host-immune response to influenza infection. These results indicate that the host response reduced the viral burden and most importantly reduced the mortality of the infection, emphasizing the therapeutic potential of inhaled GM-CSF.

\section{Should host defense or total lung function be used as endpoints?}

It has been predicted that the $\mathrm{T}_{\mathrm{H}} 1$ subset, increased by inhaled GM-CSF, is related to a much more favorable $\mathrm{FEV}_{1}$ and vital capacity (VC) in the longer run. ${ }^{5}$ Further, the change in $\mathrm{FEV}_{1}$ does not sufficiently and sensitively reflect changes in the peripheral airways, because small airways normally contribute less than $30 \%$ of the total airway resistance. ${ }^{47}$ This implies that substantial abnormalities could arise in these airways before the $\mathrm{FEV}_{1}$ becomes abnormal..$^{48,49}$ It thus appears that measurement of total lung function $\left(\mathrm{FEV}_{1}\right.$ and VC) does not, over a longer time span, reflect the changes of the small airways and alveolar environmental changes with sufficient sensitivity during the chronic infectious state. This is a most important point in the documentation of changes induced by inhaled GM-CSF, because GM-CSF exerts its effect on the alveolar macrophages. It therefore seems irrelevant to measure total lung function variables in order to reflect modifications after interventions such as inhaled GM-CSF, because measurements of $\mathrm{FEV}_{1} / \mathrm{VC}$ in a much later, irreversible phase reflect restrictive pulmonary dysfunction, such as extensive irreversible structural remodeling of small airways, with widespread bronchiectases, cyst formation, mucoid impaction, atelectasis, fibrosis, and vascular changes. ${ }^{50}$ Alternative methods reflecting the immunological changes that prevent irreversible lung function damage must therefore be applied. The measurement of total lung function should therefore be abandoned because it is irrelevant in respect to the prevention of fibrosis in the CF patient. Lung function testing should not be the monitor - on the contrary it is only the endpoint. Therefore the monitor should be the pathophysiologic variables that prevent lung fibrosis: the surrogate variables as shown in Table 2, which reflect the multiple efficacy aspects of inhaled GM-CSF.

\section{Discussion}

Treating chronic lung infections in patients with $\mathrm{CF}$ becomes an increasing challenge in spite of the increasing use of both systemic and inhaled administered antibiotics. CF patients develop intolerance and allergic reactions to a number of antibiotics, along with reduction of renal and hepatic function. Since lung tissue damage is highly associated with the inflammatory reaction induced by infection, adjunctive immuno-modulators have increasingly been considered as necessary treatment options in $\mathrm{CF}^{51}$

Since antibacterial and anti-inflammatory interventions have not led to the expected result, a paradigm shift is needed. Treatment with GM-CSF could be such a new paradigm because its mechanism of action aims at the upregulation of the alveolar host defense. Here, the functions of the alveolar macrophages are considered most important in respect to the alveolar host defense towards bacteria and fungi, because the alveolar environment is dominated by tolerance toward the Gram-negatives - the so-called T-helper subset $\mathrm{T}_{\mathrm{H}} 2$; a state which is characterized by the chronic invasion of $\mathrm{CD} 20$ cells into the alveolar space, which is reflected by the increased immunoglobulins IgG and IgE. ${ }^{52}$ Inhalation of the growth factor GM-CSF causes a transformation into the $\mathrm{T}_{\mathrm{H}} 1$ dominated subset, a change which could upregulate the pulmonary host defense even in the chronically-infected CF patient.

\section{Alveolar host defense and the alveolar environment}

The Achilles heel of CF is the infected lung with reduced clearance of bacteria, fungi, and viruses, causing progressive lung disease associated with unremitting bacterial infection, predominantly P. aeruginosa. ${ }^{53}$ The gene defect in CF affects macrophages globally due to the lack of CFTR regulation, reducing the important phagosomal acidification

Table 2 Overview of potential surrogate markers in relation to monitoring the efficacy of inhaled GM-CSF

\begin{tabular}{|c|c|c|}
\hline Overall & Variable & Sampling \\
\hline \multirow[t]{2}{*}{ Inflammation } & NO exhaled & Expiratory air sampling \\
\hline & Eosinophilic toxin & $\begin{array}{l}\text { Urine concentration of eosinophilic } \\
\text { degradation products }\end{array}$ \\
\hline Cytokines & IL-2, 4, 5, I0 og I2, IFN- $\gamma$, TNF & Blood \\
\hline Antibodies & $\lg E, \lg G$ & Blood \\
\hline Cells & Recruited from BAL fluid & FACS analysis \\
\hline \multirow[t]{2}{*}{ Biofilm formation } & QS and CFU threshold in relation to biofilm & QS, in vitro test \\
\hline & formation monitored by sputum alginate & Alginate in sputum ELISA-test \\
\hline
\end{tabular}

Abbreviations: QS, Quorum sensing; CFU, colony forming unit; BAL, bronchoalveolar lavage; ELISA, enzyme-linked immunosorbent assay; FACS, fluorescence activated cell sorting. 
and causing a reduced bactericidal activity triggered by the altered alveolar microenvironment, as underlined by the fact that the CF patient does not have an increased rate of systemic infections. ${ }^{54}$ Loss of intracellular acidification in CFTR-deficient alveolar macrophages could therefore be the explanation for the enhanced survival of bacterial loads within the phagosomal compartment. ${ }^{55}$ This apparent discrepancy between reduced alveolar macrophage function and lack of global infections may seem puzzling. However, the interaction between CFTR-affected alveolar macrophages and Gram-negative pulmonary infection precipitates a regionally-reduced pulmonary host defense. Normally alveolar macrophages induce inflammatory cytokines after exposure to Gram-negative bacteria via the TLRs. However, in CF patients, TLR4 expression in the bronchial epithelium is significantly reduced compared to healthy control subjects, which is emphasized by the finding that the TLR4 surface expression is normalized after correction of the CFTR-negative cells. ${ }^{8}$ The loss of CFTR function appears to decrease innate immune responses, possibly by altering the expression of TLR4 on airway epithelial cells, thereby contributing to chronic bacterial infection in CF airways. ${ }^{8}$

\section{The defective macrophage and the alveolar environment in the CF patient}

In a mouse model of CF based on mice infected with LPS, a defect in CF macrophage function has been suggested. The innate GM-CSF expression was reduced in CF-like mice as compared to wild-type mice, ${ }^{56}$ in line with the findings of increased mortality, and reduced phagocytosis and intracellular bacterial killing of Gram-negatives by alveolar macrophages in GM-CSF (-/-) mice. By administering GMCSF, the documented changes were reversed. ${ }^{57}$

Along with the documented dysfunctional macrophages of the CF lung, which could explain the reduced capacity to clear bacterial infecting agents, the end result could be an excessive chronic inflammatory response, the $\mathrm{T}_{\mathrm{H}} 2$ dominated response.

The alveolar cellular recruitment process may lead to either a $\mathrm{T}_{\mathrm{H}} 1$ or a $\mathrm{T}_{\mathrm{H}} 2$ cell response. The $\mathrm{T}_{\mathrm{H}} 1$ response enhances a cellular profile with cytotoxic T-cells (CD8+) and natural killer cells (CD16+ (NK-cells)), with a specific cytokine IFN- $\gamma$ pattern, ${ }^{10}$ whereas the $\mathrm{T}_{\mathrm{H}} 2$ response corresponds to a chronic hyperinflammatory state with a different cytokine profile and recruitment of CD20+ cells with production of immunoglobulins (Table 1), triggered by ongoing stimulation of the antigens mostly from Pseudomonas spp. ${ }^{10}$
The chronic local inflammatory state is dominated by the $\mathrm{T}_{\mathrm{H}} 2$ response, with activation of $\mathrm{CD} 20+$ cells, increased production of antibodies, and development of tolerance towards Gram-negative infections. ${ }^{4}$ With the alveolar tolerance towards Gram-negative bacteria, the CD14 cells characteristic of the $\mathrm{T}_{\mathrm{H}} 2$ subset induce irreversible lung fibrosis and pulmonary dysfunction typical of $\mathrm{CF}$ terminal respiratory insufficiency. ${ }^{23}$

\section{Effect of inhaled GM-CSF}

Inhaled GM-CSF can potentially enhance the complex host defense of the alveolar environment, because the drug enhances macrophage function via multiple points of action. (i) The TLR4 s acting on Gram-negative bacteria are increasingly expressed after treatment with GM-CSF, which facilitates the recognition and clearing of Gram-negatives. ${ }^{58}$ (ii) The drug increases alveolar antigen presentation by enhanced opsonization and intracellular killing of bacteria after GM-CSF administration. ${ }^{19}$ (iii) The local GM-CSF has been shown to shift T-helper response toward the essential $\mathrm{T}_{\mathrm{H}} 1$ subset, because the recruited cytotoxic (CD8) and NK-cells (CD16) from the systemic circulation may clear the infection. ${ }^{20,21}$ (iv) Inactivation of pulmonary fibroblasts (CD14). These factors combine to produce a more favorable lung function outcome. ${ }^{5}$

It also appears likely that bacterial clearance is improved by a T-helper cell switch from an immunological $\mathrm{T}_{\mathrm{H}} 2$ response to the favorable $T_{H} 1$ setting. It appears that such a shift takes place during and after the GM-CSF inhalation period as both $\operatorname{IgG}$ and $\operatorname{IgE}$ are reduced and specific IgE anti-Aspergillus antibodies are reduced during the inhalation period. ${ }^{5}$

The antibody response against $P$. aeruginos $a$ in $\mathrm{CF}$ is a marker of chronic infection, inflammation, and tissue damage. The very high sensitivity of the assays makes it possible to characterize patients with negative antibody assays as being free of chronic $P$. aeruginosa infection. ${ }^{59}$ The $\mathrm{T}_{\mathrm{H}} 2$ like immunological response also encompasses an allergic component with increased immunoglobulins that is typical for allergic bronchopulmonary aspergillosis. This condition is common in $\mathrm{CF}$, with an incidence of $10 \%$. The condition is diagnosed by increased levels of IgE, Aspergillus-specific IgE and IgG, or precipitins. ${ }^{60}$ Cohen-Cymberknoh et al found that treatment with prednisolone, which is supposed to be the treatment of choice, did not suppress the antibodies. ${ }^{61}$ With GM-CSF inhalation, on the other hand, IgE fell to almost zero and the IgG leveled out. Further it appeared that macrophage function was enhanced, because $A$. fumigatus was 
not cultured and acid-fast bacteria could not be detected in the patients' sputum for a period after the GM-CSF inhalation.

These findings strongly support the concept that inhaled GM-CSF transforms the $\mathrm{T}_{\mathrm{H}}$ 2-dominated alveolar condition into a $\mathrm{T}_{\mathrm{H}}$ 1-like response, which is in keeping with the fact that a $\mathrm{T}_{\mathrm{H}} 2$ response is seen when Aspergillus antigens appear in CF patients. ${ }^{22}$ During the GM-CSF inhalation period, stabilization of lung function $\left(\mathrm{FEV}_{1}\right)$ was noted ${ }^{45}$ However, changes in $\mathrm{FEV}_{1}$ do not sufficiently and sensitively reflect changes in the peripheral airways because small airways normally contribute less than $30 \%$ of the total airway resistance. ${ }^{47}$ Therefore substantial abnormalities could arise in these airways before $\mathrm{FEV}_{1}$ values become abnormal. ${ }^{48}$ It appears that measurements of $\mathrm{FEV}_{1}$ do not sensitively reflect changes in the environment of small airways in early stages of the disease - the point of attack of inhaled GM-CSF. Later however, $\mathrm{FEV}_{1}$ values reflect respiratory failure due predominantly to extensive irreversible structural remodeling of the small airways, with widespread bronchiectases, cyst formation, mucoid impaction, atelectasis, fibrosis, and vascular changes. ${ }^{50}$ In future, measurements of $\mathrm{FEV}_{1}$ should be combined with immunological variables (ie, surrogate variables). Inhaled GM-CSF did not produce pulmonary adverse effects in any of the published papers documenting the adverse effects of GM-CSF, ie, neither wheezing nor signs of bronchoconstriction were registered.

Inhaled GM-CSF also appears safe because aerosol therapy did not cause any adverse effects in either lung cancer or in patients with pulmonary alveolar proteinosis. ${ }^{42-44}$

\section{Surrogate markers reflecting the changes in the alveoli}

Table 2 shows the multiple points of action of inhaled GM$\mathrm{CSF}$ as they relate to future studies, most of which are aimed at monitoring the $\mathrm{T}_{\mathrm{H}} 2$ to $\mathrm{T}_{\mathrm{H}} 1$ switch.

These variables could provide a new approach to studying alterations in the alveolar environment after an intervention such as treatment with inhaled GM-CSF.

A major issue in the antibacterial strategy is that biofilm formation protects bacteria from antibiotic action. In $\mathrm{CF}$ patients there is frequent colonization with $P$. aeruginosa and the mucoid isolate forms a biofilm of which a major component is alginate. This may quantitatively be measured in sputum (Table 2). The mucoid isolate is a Pseudomonas strain that constantly signals neighboring bacteria via pheromones to produce biofilm. These colony forming units (CFU) can produce biofilm by increasing the bacterial density by a process called quorum sensing (QS). ${ }^{62}$
This adaptive "stealth" strategy counteracts the combined antibacterial action of antibiotics and the endogenous alveolar immune system.

Treatment of the mucoid strains has hitherto not been able to counteract the biofilm formation. Because inhaled GM-CSF can upregulate the peripheral airways host defense, it could, just by reducing the CFUs, reduce the amount of alginate in sputum. The in vitro QS test could prove to be a useful marker of the efficacy of GM-CSF inhalation.

\section{Conclusion}

Inhaled GM-CSF seems to be a promising new treatment to improve host defenses in patients with CF. The chronic alveolar immuno-inflammatory status with colonization is a typical $\mathrm{T}_{\mathrm{H}} 2$-dominated inflammatory response. Such a subset unfortunately appears to be tolerant of Gramnegative bacteria. After inhalation of GM-CSF, however, the T-helper cells can be transformed into the $\mathrm{T}_{\mathrm{H}} 1$ subset, as documented by reduced immunoglobulin $\operatorname{IgG}$ and $\operatorname{IgE}$ concentration in a recent study. ${ }^{45}$ The IgE concentration, which is related to allergy, was also reduced after GM-CSF inhalation, indicated by an altered cytokine pattern that showed increased TNF, IL- $1 \beta$, IFN- $\gamma$, and IL-10 concentration. Inhaled GM-CSF was regarded as the only effective administration route because IV-administered GM-CSF, like other biologics, does not pass the alveolocapillary membrane. This important fact makes it possible to achieve a direct effect on the alveolar immune inflammatory response without adverse effects in the systemic pool of immunoactive cells.

In order to elucidate the role of inhaled GM-CSF in a human controlled trial, at least in a short term study of 6 weeks, it is necessary to apply not only the classical primary endpoints but to supplement with changes in specific surrogate variables each reflecting a specific function of the host system. In such a study we find it less important to emphasize classical spirometry measurements as the primary endpoint. The expected alterations in lung function do not reflect the changes in peripheral airways and the alveolar environment after administration of inhaled GM-CSF. The overall purpose of such a study is to show that inhaled GM-CSF in chronically colonized CF patients modifies the immuno-inflammatory state and switches the $\mathrm{T}_{\mathrm{H}} 2$ subset into the favorable $\mathrm{T}_{\mathrm{H}} 1$ subset.

Continued research is clearly indicated and the role of inhaled GM-CSF in modulating the pulmonary host defense in CF patients should be investigated in a large controlled study. 


\section{Disclosure}

Lars Heslet (LH) has shares in the pharmacompany Serendex ApS Copenhagen, Denmark, which holds a patent related to inhaled GM-CSF. LH has, however, not received reimbursements, fees, or funding from any organization relating to the content or the preparation of this manuscript. LH declares that he has no other competing interests. Steen Nepper-Christensen (SNC) and Christiane Bay (CB) declare that they have no competing financial interests related to the preparation or the content of the manuscript. All authors read and approved the final manuscript.

\section{References}

1. Alexis NE, Muhlebach MS, Peden DB, Noah TL. Attenuation of host defense function of lung phagocytes in young cystic fibrosis patients. J Cyst Fibros. 2006;5(1):17-25.

2. Chmiel JF, Berger M, Konstan MW. The role of inflammation in the pathophysiology of CF lung disease. Clin Rev Allergy Immunol. 2002;23(1):5-27.

3. Hartl D, Griese M, Kappler M, et al. Pulmonary T(H)2 response in Pseudomonas aeruginosa-infected patients with cystic fibrosis. JAllergy Clin Immunol. 2006;117(1):204-211.

4. Greenberger PA. Immunologic aspects of lung diseases and cystic fibrosis. JAMA. 1997;278(22):1924-1930.

5. Moser C, Jensen PØ, Pressler T, et al. Serum concentrations of GMCSF and G-CSF correlate with the Th1/Th2 cytokine response in cystic fibrosis patients with chronic Pseudomonas aeruginosa lung infection. APMIS. 2005;113(6):400-409.

6. Knight RA, Kollnberger S, Madden B, Yacoub M, Hodson ME. Defective antigen presentation by lavage cells from terminal patients with cystic fibrosis. Clin Exp Immunol. 1997;107(3):542-547.

7. del Fresno C, Gómez-Piña V, Lores V, et al. Monocytes from cystic fibrosis patients are locked in an LPS tolerance state: downregulation of TREM-1 as putative underlying mechanism. PLOS ONE. 2008;3(7):e2667.

8. John G, Yildirim AO, Rubin BK, Gruenert DC, Henke MO. TLR-4mediated innate immunity is reduced in cystic fibrosis airway cells. $\mathrm{Am}$ J Respir Cell Mol. Biol. 2010;42(4):424-431.

9. Peterson-Carmichael SL, Harris WT, Goel R, et al. Association of lower airway inflammation with physiologic findings in young children with cystic fibrosis. Pediatr Pulmonol. 2009;44(5):503-511.

10. Brazova J, Sediva A, Pospisilova D, et al. Differential cytokine profile in children with cystic fibrosis. Clin Immunol. 2005;115(2):210-215.

11. Cuyler JP, Monaghan AJ. Cystic fibrosis and sinusitis. J Otolaryngol. 1989;18(4):173-175.

12. Fisker J, von Buchwald C, Johansen HK. [Microbial biofilm in rhinosinusitis and cystic fibrosis]. Ugeskr Laeg. 2011;173(6):417-419.

13. Saiman L, Siegel J. Infection control in cystic fibrosis. Clin Microbiol Rev. 2004;17(1):57-71.

14. Hansen CR, Pressler T, Høiby N. Early aggressive eradication therapy for intermittent Pseudomonas aeruginosa airway colonization in cystic fibrosis patients: 15 years' experience. J Cyst Fibros. 2008;7(6):523-530.

15. Nichols DP, Konstan MW, Chmiel JF. Anti-inflammatory therapies for cystic fibrosis-related lung disease. Clin Rev Allergy Immunol. 2008;35(3):135-153.

16. Calum H, Moser C, Jensen PØ, Shirai R, Høiby N. Cytokine and surface receptor diversity of $\mathrm{NK}$ cells in resistant $\mathrm{C} 3 \mathrm{H} / \mathrm{HeN}$ and susceptible $\mathrm{BALB} / \mathrm{c}$ mice with chronic Pseudomonas aeruginosa lung infection. APMIS. 2003;111(9):891-897.

17. Spellberg B, Edwards JE Jr. Type 1/Type 2 immunity in infectious diseases. Clin Infect Dis. 2001;32(1):76-102.
18. Moser C, Hougen HP, Song Z, Rygaard J, Kharazmi A, Hoiby N. Early immune response in susceptible and resistant mice strains with chronic Pseudomonas aeruginosa lung infection determines the type of T-helper cell response. APMIS. 1999;107(12):1093-1100.

19. Eksioglu EA, Mahmood SS, Chang M, Reddy V. GM-CSF promotes differentiation of human dendritic cells and $\mathrm{T}$ lymphocytes toward a predominantly type 1 proinflammatory response. Exp Hematol. 2007;35(8):1163-1171.

20. Gonzalez-Juarrero M, Hattle JM, Izzo A, et al. Disruption of granulocyte macrophage-colony stimulating factor production in the lungs severely affects the ability of mice to control Mycobacterium tuberculosis infection. J Leukoc Biol. 2005;77(6):914-922.

21. Trapnell BC, Whitsett JA. Gm-CSF regulates pulmonary surfactant homeostasis and alveolar macrophage-mediated innate host defense. Annu Rev Physiol. 2002;64:775-802.

22. Knutsen AP, Bellone C, Kauffman H. Immunopathogenesis of allergic bronchopulmonary aspergillosis in cystic fibrosis. J Cyst Fibros. 2002;1(2):76-89.

23. Meneghin A, Hogaboam CM. Infectious disease, the innate immune response, and fibrosis. J. Clin. Invest. 2007;117(3):530-538.

24. Johansen HK, Hougen HP, Rygaard J, Høiby N. Interferon-gamma (IFN-gamma) treatment decreases the inflammatory response in chronic Pseudomonas aeruginosa pneumonia in rats. Clin Exp Immunol. 1996;103(2):212-218.

25. Ueno H, Klechevsky E, Morita R, et al. Dendritic cell subsets in health and disease. Immunol Rev. 2007;219:118-142.

26. Grunig G, Banz A, de Waal Malefyt R. Molecular regulation of Th2 immunity by dendritic cells. Pharmacol Ther. 2005;106(1):75-96.

27. Caux C, Dezutter-Dambuyant C, Schmitt D, Banchereau J. GM-CSF and TNF-alpha cooperate in the generation of dendritic Langerhans cells. Nature. 1992;360(6401):258-261.

28. Mariotti S, Sargentini V, Marcantonio C, et al. T-cell-mediated and antigen-dependent differentiation of human monocyte into different dendritic cell subsets: a feedback control of Th1/Th2 responses. FASEB J. 2008;22(9):3370-3379.

29. Zhang P, Summer WR, Bagby GJ, Nelson S. Innate immunity and pulmonary host defense. Immunol Rev. 2000;173:39-51.

30. Medzhitov R, Janeway C Jr. Innate immunity. $N$ Engl J Med. 2000;343(5):338-344.

31. Heslet L. Look on the "air side" in pneumonia. Crit Care Med. 2009;37(2):774-775.

32. Rose RM, Kobzik L, Dushay K, et al. The effect of aerosolized recombinant human granulocyte macrophage colony-stimulating factor on lung leukocytes in nonhuman primates. Am Rev Respir Dis. 1992;146(5 Pt 1):1279-1286.

33. Brand P, Beckmann H, Maas Enriquez M, et al. Peripheral deposition of alpha1-protease inhibitor using commercial inhalation devices. Eur Respir J. 2003;22(2):263-267.

34. Liu KD, Levitt J, Zhuo H, et al. Randomized clinical trial of activated protein $\mathrm{C}$ for the treatment of acute lung injury. Am J Respir Crit Care Med. 2008;178(6):618-623.

35. Heslet L, Andersen JS, Sengeløv H, Dahlbäck B, Dalsgaard-Nielsen J. Inhalation of activated protein $\mathrm{C}$ : A possible new adjunctive intervention in acute respiratory distress syndrome. Biologics. 2007;1(4):465-472.

36. Waerhaug K, Kuzkov VV, Kuklin VN, et al. Inhaled aerosolised recombinant human activated protein $\mathrm{C}$ ameliorates endotoxin-induced lung injury in anaesthetised sheep. Crit Care. 2009;13(2):R51.

37. Kitamura T, Tanaka N, Watanabe J, et al. Idiopathic pulmonary alveolar proteinosis as an autoimmune disease with neutralizing antibody against granulocyte/macrophage colony-stimulating factor. J Exp Med. 1999;190(6):875-880.

38. Rodríguez Portal JA, Rodríguez Becerra E, Sánchez Garrido A. Response to inhaled granulocyte-macrophage colony-stimulating factor in a patient with alveolar proteinosis. Arch Bronconeumol. 2009;45(3):150-152. Spanish.

39. Ioachimescu OC, Kavuru MS. Pulmonary alveolar proteinosis. Chron Respir Dis. 2006;3(3):149-159. 
40. Sangwan S, Agosti JM, Bauer LA, et al. Aerosolized protein delivery in asthma: gamma camera analysis of regional deposition and perfusion. J Aerosol Med. 2001;14(2):185-195.

41. Luisetti M, Kroneberg P, Suzuki T, et al. Physical properties, lung deposition modeling, and bioactivity of recombinant GM-CSF aerosolised with a highly efficient nebulizer. Pulm Pharmacol Ther. 2011;24(1):123-127.

42. Anderson PM, Markovic SN, Sloan JA, et al. Aerosol granulocyte macrophage-colony stimulating factor: a low toxicity, lung-specific biological therapy in patients with lung metastases. Clin Cancer Res. 1999;5(9):2316-2323.

43. Wylam ME, Ten R, Prakash UBS, et al. Aerosol granulocyte-macrophage colony-stimulating factor for pulmonary alveolar proteinosis. Eur Respir J. 2006;27(3):585-593.

44. Rao RD, Anderson PM, Arndt CAS, Wettstein PJ, Markovic SN. Aerosolized granulocyte macrophage colony-stimulating factor (GM-CSF) therapy in metastatic cancer. Am J Clin Oncol. 2003;26(5):493-498.

45. Moser C, Jensen PØ, Pressler T, Høiby N. Adjunctive treatment with GM-CSF of CF patients with severe Mycobacterium abscessus lung infection. The 19th Annual North American Cystic Fibrosis Conference, Baltimore, MD, October 20-23. Pediatr Pulmonol. 2005;(Suppl 28): (239)272.

46. Huang F-F, Barnes PF, Feng Y, et al. GM-CSF in the lung protects against lethal influenza infection. Am J Respir Crit Care Med. 2011;184(2):259-268.

47. Cochrane GM, Benatar SR, Davis J, Collins JV, Clark TJ. Correlation between tests of small airway function. Thorax. 1974;29(2):172-178.

48. Macklem PT, Mead J. Resistance of central and peripheral airways measured by a retrograde catheter. J Appl Physiol. 1967;22(3):395-401.

49. Heslet L. Lung function inhomogeneity. A study of the pattern of single breath nitrogen washout test and radio-spirometry. Dan Med Bull. 1983;30(4):242-258.

50. Regamey N, Hilliard TN, Saglani S, et al. Quality, size, and composition of pediatric endobronchial biopsies in cystic fibrosis. Chest. 2007;131(6):1710-1717.

51. Sharma S, Jaffe A, Dixon G. Immunomodulatory effects of macrolide antibiotics in respiratory disease: therapeutic implications for asthma and cystic fibrosis. Paediatr Drugs. 2007;9(2):107-118.
52. Szeliga J, Daniel DS, Yang C-H, et al. Granulocyte-macrophage colony stimulating factor-mediated innate responses in tuberculosis. Tuberculosis (Edinb). 2008;88(1):7-20.

53. Heijerman $H$. Infection and inflammation in cystic fibrosis: a short review. J Cyst Fibros. 2005;4 Suppl 2:3-5.

54. Chapron J, Zuber B, Kanaan R, et al. Management of acute and severe complications in adults with cystic fibrosis. Rev Mal Respir. 2011;28(4):503-516. French.

55. Di A, Brown ME, Deriy LV, et al. CFTR regulates phagosome acidification in macrophages and alters bactericidal activity. Nat Cell Biol. 2006;8(9):933-944.

56. Bruscia EM, Zhang P-X, Ferreira E, et al. Macrophages directly contribute to the exaggerated inflammatory response in cystic fibrosis transmembrane conductance regulator-/- mice. Am J Respir Cell Mol. Biol. 2009;40(3):295-304.

57. Ballinger MN, Paine R 3rd, Serezani CHC, et al. Role of granulocyte macrophage colony-stimulating factor during gram-negative lung infection with Pseudomonas aeruginosa. Am J Respir Cell Mol. Biol. 2006;34(6):766-774.

58. Bozinovski S, Jones JE, Vlahos R, Hamilton JA, Anderson GP. Granulocyte/macrophage-colony-stimulating factor (GM-CSF) regulates lung innate immunity to lipopolysaccharide through Akt/Erk activation of NFkappa B and AP-1 in vivo. J Biol Chem. 2002;277(45):42808-42814.

59. Pressler T, Karpati F, Granström M, et al. Diagnostic significance of measurements of specific IgG antibodies to Pseudomonas aeruginosa by three different serological methods. J Cyst Fibros. 2009;8(1):37-42.

60. Barton RC, Hobson RP, Denton M, et al. Serologic diagnosis of allergic bronchopulmonary aspergillosis in patients with cystic fibrosis through the detection of immunoglobulin G to Aspergillus fumigatus. Diagn Microbiol Infect Dis. 2008;62(3):287-291.

61. Cohen-Cymberknoh M, Blau H, Shoseyov D, et al. Intravenous monthly pulse methylprednisolone treatment for ABPA in patients with cystic fibrosis. J Cyst Fibros. 2009;8(4):253-257.

62. Lee B, Schjerling CK, Kirkby N, et al. Mucoid Pseudomonas aeruginosa isolates maintain the biofilm formation capacity and the gene expression profiles during the chronic lung infection of CF patients. APMIS. 2011;119(4-5):263-274.
Journal of Inflammation Research

\section{Publish your work in this journal}

The Journal of Inflammation Research is an international, peer-reviewed open-access journal that welcomes laboratory and clinical findings on the molecular basis, cell biology and pharmacology of inflammation including original research, reviews, symposium reports, hypothesis formation and commentaries on: acute/chronic inflammation; mediators of inflamma-

\section{Dovepress}

tion; cellular processes; molecular mechanisms; pharmacology and novel anti-inflammatory drugs; clinical conditions involving inflammation. The manuscript management system is completely online and includes a very quick and fair peer-review system. Visit http://www.dovepress.com/ testimonials.php to read real quotes from published authors. 